NBER WORKING PAPER SERIES

\title{
WHY DO REAL AND NOMINAL INVENTORY-SALES RATIOS HAVE DIFFERENT TRENDS?
}

\author{
Valerie A. Ramey \\ Daniel J. Vine \\ Working Paper 10703 \\ http://www.nber.org/papers/w10703

\section{NATIONAL BUREAU OF ECONOMIC RESEARCH 1050 Massachusetts Avenue Cambridge, MA 02138} \\ August 2004
}

We have benefited from helpful discussions with Chad Jones and Charles Steindel. Valerie Ramey gratefully acknowledges support from the National Science Foundation Grant \#0213089. Opinions expressed here are those of the authors and not those of the Board of Governors of the Federal Reserve System. The views expressed herein are those of the author(s) and not necessarily those of the National Bureau of Economic Research.

(C)2004 by Valerie A. Ramey and Daniel J. Vine. All rights reserved. Short sections of text, not to exceed two paragraphs, may be quoted without explicit permission provided that full credit, including (C) notice, is given to the source. 
Why Do Real and Nominal Inventory-Sales Ratios Have Different Trends?

Valerie A. Ramey and Daniel J. Vine

NBER Working Paper No. 10703

August 2004

JEL No. E220

\begin{abstract}
This note explains the diverging trends between real and nominal aggregate inventory-sales ratios.

The combined effect of two features of the data explains the divergence. First, while aggregate sales include both goods and services, inventories include only goods. Second, there has been a strong secular decrease in the relative price of goods. The combination of these two factors causes the real and nominal aggregate inventory-sales ratios to have different trends.
\end{abstract}

\author{
Valerie A. Ramey \\ Department of Economics, 0508 \\ University of California, San Diego \\ 9500 Gilman Drive \\ La Jolla, CA 92093-0508 \\ and NBER \\ vramey@ucsd.edu \\ Daniel J. Vine \\ Mail Stop 82 \\ Federal Reserve Board of Governors \\ $20^{\text {th }}$ and C Streets, NW \\ Washington, DC 20551 \\ daniel.j.vine@frb.gov
}


Business and academic economists closely watch the inventory-sales ratio as a portent of future production, a remnant of past mistakes, and a measure of supply chain efficiency. Specifically, the downward trend in the US inventory-sales ratio is often offered as evidence that information technology is fundamentally changing the US economy. For example, Federal Express presents the following quote from SRI International on its web page: "The impact of the Supply Chain Revolution on firms' ability to trim excess inventories is manifested in the steady, downward trend in U.S. inventory-to-sales ratio over the past two decades."

The evidence is not so clear, however. The inventory-sales ratio consists of a stock variable divided by a flow variable, which means that it is measured in units of time, such as the number of days of sales held in inventory. "Time" should not depend on whether sales and inventories are both measured in real or nominal dollars. Yet as pointed out by Ramey and West in the 1999 Handbook of Macroeconomics chapter on inventories, the trends in real and nominal aggregate inventory to final sales ratios are very different.

Consider the behavior of the inventory-sales ratios shown in Figure 1. ${ }^{1}$ While the ratio of current dollar (nominal) nonfarm inventories to final sales shows a significant downward trend starting in the early 1980s, the 1996 chained dollar (real) ratio shows no such trend. According to the real ratio, the aggregate inventory-sales ratio was no lower in 2003 than it was in 1950. Most business discussions of the inventory-sales ratio use current dollar numbers from the National Income and Product Accounts (NIPA) or from the Census M3 reports for manufacturing and trade. Most inventory research in economics, on the other hand, uses real chained-dollar data from the Bureau of Economic Analysis (BEA).

\footnotetext{
${ }^{1}$ Data for Figures 1 and 2 were obtained from the NIPA accounts in November 2003.
} 


\section{Figure 1. Ratio of Nonfarm Inventories to Final Sales}

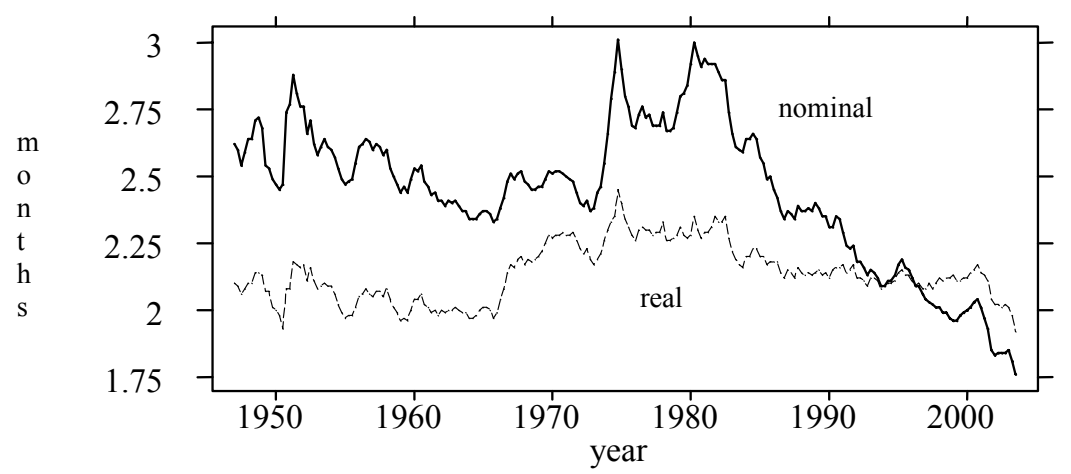

Despite the very different pictures presented by these two series, there has been little discussion of the source of the differences or of which measure most accurately reflects the historical trend in US inventories. Understanding why the nominal and real ratios have such different trends is important for resolving a number of controversies involving the role of inventories in the business cycle in recent decades. It is widely believed that the information technology (IT) revolution has led to a substantial decline in inventory-sales ratios. Moreover, the changing behavior of inventories is also a prime suspect in the decline in GDP volatility since 1984 (Kahn, McConnell, Perez-Quiros 2002). Thus, several key theories and explanations depend crucially on the behavior of the inventory-sales ratio.

This note offers an explanation for the difference between nominal and real aggregate inventory-sales ratio trends. Simply stated, the aggregate inventory-sales ratio includes services in the denominator, but not in the numerator, since services cannot be stored. Although the real share of sales that come from industries that hold inventories has changed over time, its behavior is not the source of the difference in trends between the real and nominal inventory-sales ratio in U.S. data. Rather, it is the strong secular decrease in the relative price of goods and structures that is at the heart of the discrepancy. 
At first glance, one might suspect that using chained-dollar price deflators is problematic. As the BEA points out, chain-weighted data should not be aggregated by simple addition. Chain-weighted data have the advantage, however, of giving the most accurate depiction of growth of real quantities over time. Since the inventory-sales ratio is a ratio of two quantities rather than a sum, chain-weighted data do give an accurate representation of the growth trends in the inventory-sales ratio, though perhaps not of the level at any point in time.

A few simple equations and graphs make the argument clear. Let $H$ denote the real level of inventories, $S$ denote the real level of final sales, and $P$ denote the price level. The subscript $g$ stands for goods plus structures and the subscript $v$ stands for services. The real inventory sales ratio is given by:

$$
\text { Real inventory-sales ratio }=\frac{H_{t}}{S_{t}}=\frac{H_{g t}}{S_{t}} .
$$

The numerator includes only inventories of goods and structures, while the denominator includes final sales of goods, structures and services. In the data, the denominator is the chained dollar value of final sales in year $t$. Its growth is related to the growth rates of sectoral sales according to the following formula: ${ }^{2}$

$$
S_{t}=S_{t-1} \cdot \sqrt{\frac{P_{g t} S_{g t}+P_{v t} S_{v t}}{P_{g t} S_{g t-1}+P_{v t} S_{v t-1}} \cdot \frac{P_{g t-1} S_{g t}+P_{v t-1} S_{v t}}{P_{g t-1} S_{g t-1}+P_{v t-1} S_{v t-1}}}
$$

The real dollar value of sales is computed by applying this formula to nominal sales in a base year (1996 for our data), and extending the series backward and forward.

In contrast, the nominal inventory sales ratio can be written as:

$$
\text { Nominal inventory-sales ratio }=\frac{P_{g t} \cdot H_{g t}}{P_{t} \cdot S_{t}}=\left(\frac{P_{g t}}{P_{t}}\right) \cdot\left(\frac{H_{g t}}{S_{t}}\right) .
$$

\footnotetext{
${ }^{2}$ See Whelan (2000) for a useful discussion of chain-weighted data.
} 
Thus, the nominal inventory-sales ratio is equal to the real inventory-sales ratio multiplied by the price of goods and structures relative to goods, structures and services, $\left(\mathrm{P}_{\mathrm{g}} / \mathrm{P}\right)$.

The BEA also publishes inventory-sales ratios that use final sales of only goods and structures in the denominator. Figure 2 shows the behavior of the real and nominal versions of this ratio. There is little difference between these ratios because the price deflators for the numerator and denominator are the same. The patterns in both inventory-sales ratios show a general increase until 1980 and then a decline that begins in the 1980s and continues through the 1990s so that they now stand at their levels in the 1950s.

\section{Figure 2. Ratio of Nonfarm Inventories to Final Sales of Goods and Structures}

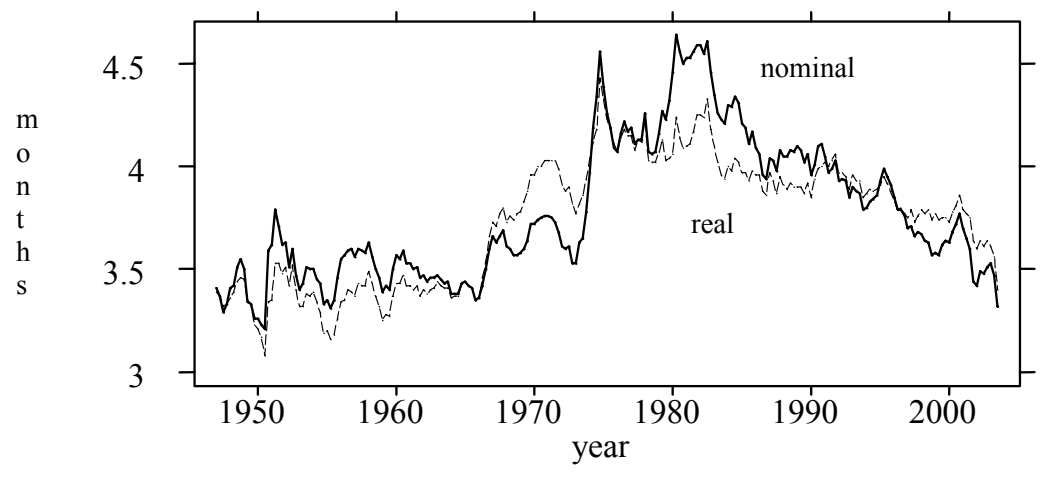

Consider next the relative price of goods and structures to all final sales, $P_{g} / P$, which affects only the broader nominal inventory-sales ratio. Figure 3 displays the history of this ratio in US quarterly data. ${ }^{3}$ The relative price of goods and structures decreased by 37 percent since

\footnotetext{
${ }^{3}$ The price deflators are constructed by dividing current dollar final sales by chained dollar final sales. For the goods plus structures aggregate, we constructed chained-dollar data using a version of the chain-weighting formula shown earlier in which the two sub-sectors were goods and structures.
} 
1947. Moreover, it decreased at a faster rate in the post-1980 period, the same time that the real and nominal inventory-sales ratios show the largest discrepancies.

\section{Figure 3. Relative Price of Goods and Structures}

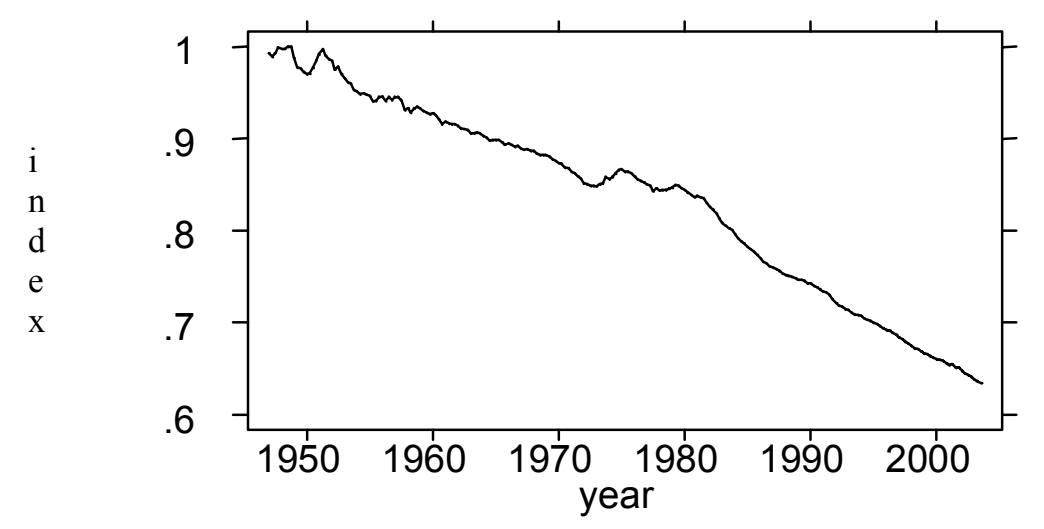

Thus, the culprit behind the aggregate real and nominal inventory-sales ratio trend discrepancies is evident. The price of goods and structures has decreased relative to services in the post-WWII period. This decrease causes the nominal inventory-sales ratio to diverge from the real inventory-sales ratio because services appear only in the denominator.

Which inventory-sales ratio should one use, real or nominal? While the level of the inventory-sales ratio at any particular point in time is best measured in current dollars (so the relative prices are correct), comparisons of the inventory-sales ratio between different points in history, including the measurement of growth trends, is best done with the chained-dollar inventory-sales ratio. The trend in the nominal ratio is impacted by relative price changes, and hence can be very misleading.

For many purposes, such as studying the historical effects of information technology on inventory holdings or the connection between inventory-sales trends and business cycle 
volatility, the chain-weighted ratio is the correct ratio to use. On the other hand, the nominal ratio may be more appropriate for some studies of credit and working capital requirements for financing the dollar value of inventories. For studies of inventory-sales ratios of more homogenous goods, such as for manufactured goods, both nominal and real ratios should present similar pictures since changes in relative prices are not an issue. Other aggregation issues might come into play, though. As discussed by Irvine (2003), shifts in the share of sales across sectors with different inventory-sales ratios can lead the aggregate inventory-sales ratio to behave differently from the disaggregated ratios. 


\section{LITERATURE CITED}

Irvine, F. Owen. (2003) "Long Term Trends in US Inventory to Sales Ratios." International Journal of Production Economics, 81-82, 27-39.

Kahn, James A., Margaret M. McConnell and Gabriel Perez-Quiros. (2002) "On the Causes of the Increased Stability of the U.S. Economy." FRBNY Economic Policy Review, 8:1,183-202.

Ramey, Valerie A. and Kenneth D. West. (1999) "Inventories." In Handbook of Macroeconomics, edited by John D. Taylor and Michael Woodford, pp. 863-923. Amsterdam: Elsevier Science Press.

Whelan, Karl. (2000) "A Guide to the Use of Chain Aggregate NIPA Data" Federal Reserve Board of Governors Finance and Economics Discussion Series, 2000-35. 